\title{
Chronic constipation diagnosis and treatment evaluation: the "CHRO.CO.DI.T.E." study
}

\author{
Massimo Bellini ${ }^{1 *}$, Paolo Usai-Satta ${ }^{2}$, Antonio Bove ${ }^{3}$, Renato Bocchini ${ }^{4}$, Francesca Galeazzi ${ }^{5}$, Edda Battaglia ${ }^{6}$,
} Pietro Alduini ${ }^{7}$, Elisabetta Buscarini ${ }^{8}$, Gabrio Bassotti ${ }^{9}$ and ChroCoDiTE Study Group, AIGO

\begin{abstract}
Background: According to Rome criteria, chronic constipation (CC) includes functional constipation (FC) and irritable bowel syndrome with constipation (IBS-C). Some patients do not meet these criteria (No Rome Constipation, NRC). The aim of the study was is to evaluate the various clinical presentation and management of FC, IBS-C and NRC in Italy.

Methods: During a 2-month period, 52 Italian gastroenterologists recorded clinical data of FC, IBS-C and NRC patients, using Bristol scale, PAC-SYM and PAC-QoL questionnaires. In addition, gastroenterologists were also asked to record whether the patients were clinically assessed for CC for the first time or were in follow up. Diagnostic tests and prescribed therapies were also recorded.

Results: Eight hundred seventy-eight consecutive CC patients (706 F) were enrolled (FC 62.5\%, IBS-C 31.3\%, NRC 6. 2\%). PAC-SYM and PAC-QoL scores were higher in IBS-C than in FC and NRC. $49.5 \%$ were at their first gastroenterological evaluation for CC. In 48.5\% CC duration was longer than 10 years. A specialist consultation was requested in 31.6\%, more frequently in IBS-C than in NRC. Digital rectal examination was performed in only $56.4 \%$. Diagnostic tests were prescribed to $80.0 \%$. Faecal calprotectin, thyroid tests, celiac serology, breath tests were more frequently suggested in IBS-C and anorectal manometry in FC. More than $90 \%$ had at least one treatment suggested on chronic constipation, most frequently dietary changes, macrogol and fibers. Antispasmodics and psychotherapy were more frequently prescribed in IBS-C, prucalopride and pelvic floor rehabilitation in FC.

Conclusions: Patients with IBS-C reported more severe symptoms and worse quality of life than FC and NRC. Digital rectal examination was often not performed but at least one diagnostic test was prescribed to most patients. Colonoscopy and blood tests were the "first line" diagnostic tools. Macrogol was the most prescribed laxative, and prucalopride and pelvic floor rehabilitation represented a "second line" approach. Diagnostic tests and prescribed therapies increased by increasing CC severity.
\end{abstract}

Keywords: Functional constipation, Irritable bowel syndrome, Diagnosis, Treatment

\footnotetext{
* Correspondence: mbellini@med.unipi.it

${ }^{1}$ Gastrointestinal Unit, Department of Gastroenterology, University of Pisa, Via

Paradisa, 2, 56127 Pisa, Italy

Full list of author information is available at the end of the article
} 


\section{Background}

Chronic constipation (CC) is a common and extremely troublesome disorder that has a negative impact on social and professional life, reduces the quality of life (QoL) and represents a heavy economic burden [1-5]. CC affects about $12-17 \%$ of the world population, with a higher prevalence among females and elderly people [6-9].

A considerable amount (16 to $40 \%$ ) of CC patients in different countries use laxatives, and their use is related to increasing age, symptom frequency and duration of constipation; in the USA more than $\$ 800$ million are spent on laxatives each year $[10,11]$.

The most widely used criteria to assess CC are the Rome Criteria [12] (Table 1) which separate constipation in functional constipation (FC) and irritable bowel syndrome with constipation (IBS-C). The presence of abdominal pain relieved by defecation characterizes IBS-C. Moreover, some patients consider themselves constipated even when not showing signs or symptoms consistent with Rome criteria (here defined as "NoRome Constipation", NRC) [13].

Table 1 Rome III criteria for functional constipation and irritable bowel syndrome

Functional Constipation

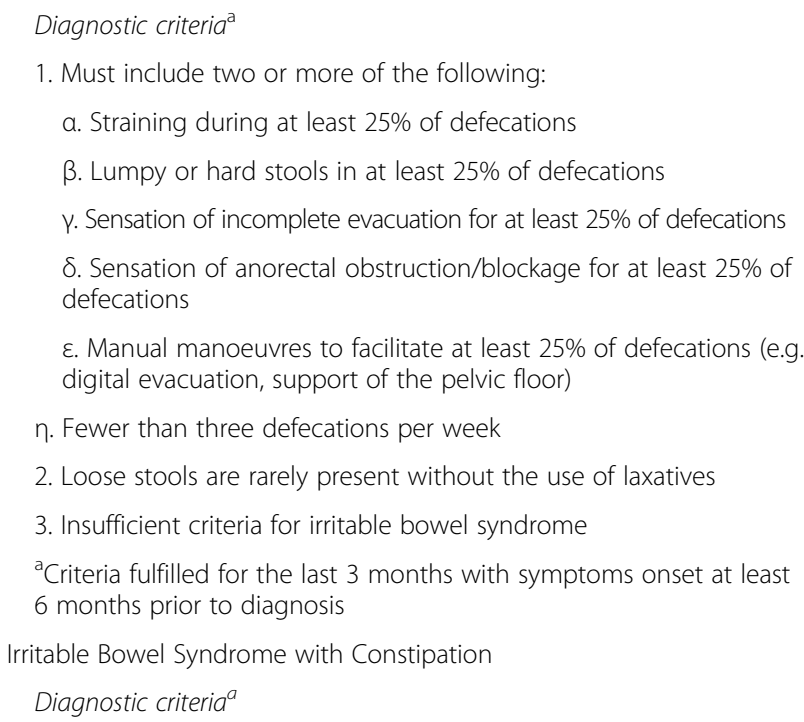

${ }^{a}$ Criteria fulfilled for the last 3 months with symptoms onset at least 6 months prior to diagnosis

b "Discomfort" means an uncomfortable sensation not described as pain
At present it is unclear whether gastroenterologists use the same diagnostic and therapeutic approach in these different groups of patients.

\section{Objective of the study \\ Primary endpoints}

- To describe the diagnostic tools used and the treatments suggested by Italian gastroenterologists for CC patients.

\section{Secondary endpoints}

- To assess, among CC patients, the distribution of FC, IBS-C and NRC and the severity of symptoms and QoL.

- To evaluate whether the diagnosis of FC, IBS-C and NRC could affect the use of the diagnostic tools and the choice of the therapy.

- To evaluate other possible potential factors affecting the use of the diagnostic tools and the therapeutic choices in CC patients.

\section{Methods}

\section{Study population and questionnaires}

Fifty two gastroenterologists belonging to different gastroenterological units in Italy on behalf of the Italian Association of Hospital Gastroenterologists and Endoscopists (AIGO), recorded clinical and demographic data of all patients consecutively referred for CC in a two month period (September-October 2013).

Bristol scale [14] was used to assess the stool consistency in the previous three months, while symptoms were classified according to Rome III criteria in order to verify whether the patients could be diagnosed as FC, IBS-C, or NRC. In addition, gastroenterologists were also asked to record whether the patients were clinically assessed for CC for the first time or were in follow up. Diagnostic tests, recommended specialist consultations and prescribed therapies were also recorded.

Furthermore, patients were required to fill the Patient Assessment of Constipation-Symptoms (PAC-SYM) and the Patient Assessment of Constipation-Quality of Life (PAC-QoL) questionnaires.

PAC-SYM is a 12-item self-reported questionnaire developed to assess the frequency and severity of CC symptoms. It is divided into three symptom subscales: abdominal (items 1-4), rectal (items 5-7), and stool (items 8-12) [15].

PAC-QoL is a 28 item self-reported questionnaire used to measure the patient's QoL. It is divided into four subscales: physical discomfort (items 1-4), psychosocial discomfort (items 5-12), worries and concerns (items 12-23), and satisfaction (items 24-28) [16]. 
For both questionnaires, items are scored on a fivepoint Likert scale $(0-4)$, with 4 indicating the worst symptom severity.

\section{Inclusion criteria}

-Patients aged over 18 years evaluated for CC.

\section{Exclusion criteria}

-Presence of known or suspected severe organic disease potentially causing constipation and/or psychiatric disease potentially interfering with questionnaires compilation.

-Patients assuming potentially constipating drugs or the onset of constipation after starting any kind of drug.

\section{Statistical analysis}

Data were analyzed by means of the $\mathrm{SAS}^{\circ}$ System for Windows, version 9.2.

A prevalence approach was adopted and no imputation was performed for any missing data.

The association between categorical variables was analyzed using Chi-Square test or Fisher's exact test (for cell frequencies $<5$ ). In order to correct for multiple comparisons, pairwise tests were adjusted using the Bonferroni method.

The association between a continuous and a categorical variable (with two categories) was analyzed by the Wilcoxon-Mann-Whitney test. Finally, the association between a continuous and a categorical variable was analyzed by the Kruskal-Wallis test (or by the ANOVA in case of normal distribution). In case of pairwise comparisons, the Dunn's test was performed. The correlation between two continuous variables was summarized by the Pearson's correlation coefficient in case of normal data distribution, or by the Spearman's correlation coefficient otherwise.

All statistical tests were performed with a two-sided significance level $\alpha=0.05$, therefore $p$-values lower than 0.05 were considered statistically significant.

The PAC-SYM and PAC-QoL total and domain scores were calculated as detailed in Additional file 1, respectively.

PAC-SYM total score and PAC-QoL total score were also analyzed through multivariate regression models, adjusting for the following independent variables: age, sex, diagnosis, duration of CC.

\section{Results}

Data from 878 CC patients $33.9 \%$ in Northern Italy, $32.4 \%$ in Center Italy and $33.7 \%$ in Southern Italy), 706 women $(80.4 \%)$ and 172 men (19.6\%), mean age: $51.0 \pm 16.8$ years (F $49.6 \pm 16.6$ years; M $56.9 \pm$ 16.5 years) were obtained. Their body mass index (BMI) was $23.7 \pm 4.0 \mathrm{~kg} / \mathrm{m}^{2}$. Four hundred thirty-five out of 878 patients (49.5\%) were at their first gastroenterological evaluation for CC. According to Rome III criteria the patients were classified as FC: 549 (62.5\%); IBS-C: 275 (31.3\%); NRC: 54 (6.2\%).

IBS-C patients were younger $(46.9 \pm 16.2$ years) than FC $(52.8 \pm 16.6)$ and NRC $(53.1 \pm 18.6) \quad(p<0.0001)$. The gender distribution was significantly different between the three groups (IBS-C: women 234/275 (85.1\%); FC: women 433/549 (78.9\%); NRC: women 39/54 $(72.2 \%)(p<0.05)$.

The duration of CC was ">1-4 years" in $23.1 \%$ (IBS-C: 33.0\%; FC: 59.1\%; NRC: $7.9 \%$ ), " $\geq 5$ years" in $21.1 \%$ (IBSC: $27.0 \%$; FC: $65.4 \%$; NRC: $7.6 \%$ ) and ">10 years" in $48.5 \%$ of the patients (IBS-C: $32.2 \%$; FC: $63.9 \%$; NRC: $4.0 \%$. No significant difference was observed between groups but only a trend toward a shorter duration in NRC could be detected.

Bristol 1-2 was reported in 628/878 (71.5\%) patients (IBS-C: 208/275, 75.6\%; FC:394/549, 71.8\%; NRC: 26/54, 48.2\%) (IBS-C vs FC: ns; IBS-C vs. NRC: $p<0.001$; FC vs NRC: $p<0.005)$.

As shown in Table 2, 73.2\% of patients reported at least one comorbidity in the previous year: depression and anxiety were more frequent in IBS-C compared to FC $(p<0.01)$ and NRC $(p<0.005)$, as well as dyspepsia ( $p<0.05$ vs. FC and NRC). Gastroesophageal reflux disease was more frequent in IBS-C compared to NRC $(p<0.01)$ and in FC compared to NRC $(p<0.05)$. Hypertension was found more frequently in $\mathrm{FC}$ than in IBS-C $(p<0.05)$.

The results of PAC-SYM are shown in Table 3: IBS-C mean total score was higher than FC and NRC $(p<0.0001)$ ones. The multivariate regression model suggested that the total score of PAC-SYM (mean: $1.6 \pm 0.7$ ) was directly related to the duration of constipation $(p<0.01)$, and to younger age $(p<0.0001)$. Abdominal symptoms subscale was significantly higher in IBS-C than in FC $(p<0.05)$ and in NRC $(p<0.0001)$. In particular, a positive association was detected between each of the first four items (discomfort, pain, bloating and stomach cramps) which constitutes the abdominal subscale and IBS-C $(p<0.0001)$. Fecal symptoms subscale was significantly higher in FC and IBS-C than NRC $(p<0.01)$. Furthermore, there was a positive correlation of the total PAC-SYM score with the number of diagnostic tests $(p<0.0005)$ and of suggested therapies $(p<0.05)$.

In Table 4 the results of PAC-QoL are shown: IBS-C mean total score was higher than FC and NRC $(p<0.001)$; all the subscales, excluding the satisfaction subscale, were significantly higher in IBS-C and in FC than in NRC. Moreover, the multivariate regression model for the total score of PAC-QoL (mean: $1.8 \pm 0.7$ ) shows that this was neither related to 
Table 2 Prevalence of comorbidities

\begin{tabular}{|c|c|c|c|c|}
\hline & IBS-C: 275 & FC: 549 & NRC: 54 & $p$-value \\
\hline Dyspepsia & $128(46.5 \%)$ & $200(36.4 \%)$ & $14(25.9 \%)^{\#}$ & $<0.005$ \\
\hline Depression/anxiety & $111(40.4 \%)$ & $164(29.9 \%)^{*}$ & $9(16.7 \%)^{* *}$ & $<0.0005$ \\
\hline GERD & $98(35.6 \%)$ & 167 (30.4\%) & $8(14.8 \%)^{\# \# \# \# \#}$ & $<0.01$ \\
\hline Sleep disturbances & $87(31.6 \%)$ & $141(25.7 \%)$ & $13(24.1 \%)$ & ns \\
\hline Hypertension & $45(16.4 \%)$ & $135(24.6 \%)^{\S}$ & $11(20.4 \%)$ & $<0.05$ \\
\hline Urinary disturbances & $52(18.9 \%)$ & 115 (20.9\%) & $8(14.8 \%)$ & ns \\
\hline Thyroid disease & $26(9.4 \%)$ & $65(11.8 \%)$ & $6(11.1 \%)$ & ns \\
\hline Vaginitis & $29(10.5 \%)$ & $46(8.4 \%)$ & $4(7.4 \%)$ & ns \\
\hline Dyspareunia & $30(10.9 \%)$ & $38(6.9 \%)$ & $4(7.4 \%)$ & ns \\
\hline Diabetes & $7(2.5 \%)$ & $29(5.3 \%)$ & $3(5.6 \%)$ & ns \\
\hline Fibromyalgia & $16(5.8 \%)$ & $18(3.3 \%)$ & - & ns \\
\hline Other & $36(13.1)$ & $56(10.2 \%)$ & $7(13 \%)$ & ns \\
\hline
\end{tabular}

IBS-C irritable bowel syndrome with constipation, FC functional constipation, NRC patients do not accomplish Rome III criteria, GERD gastroesophageal reflux disease

${ }^{1} p$ values are referred to the differences between IBS-C, FC and NRC groups, in particular

${ }^{*} p<0.01$ vs IBS-C; ${ }^{* *} p<0.005$ vs IBS-C; \#p $<0.05$ vs IBS-C and FC; \#\#p $<0.01$ vs IBS-C

$\# \# \#<0.05$ vs FC; $\S p<0.05$ vs IBS-C; ns: not statistically significant

gender, nor to age or duration of constipation. There was a statistically significant positive correlation with the number of diagnostic tests $(p<0.05)$, the number of suggested therapies $(p<0.0001)$ and the number of specialist consultations $(p<0.005)$.

Digital rectal examination (DRE) was performed in $495 / 878$ (56.4\%), independently from the patients being at their first evaluation $(54.7 \%)$ or at a follow up visit $(56.6 \%)$. No relationship with gender was found (104 M: 61.3\%; F 391: 55.2\%). Patients in whom a DRE was performed were older $(52.6 \pm 16.6$ years vs. $49.4 \pm 16.7 ; p<0.01$ ), and DRE was more often performed by gastroenterologists aged over 40 years than by younger ones $(60.1 \%$ vs. $44.6 \% ; p<0.0001)$.

At least a specialist consultation was requested in 277/878 (31.6\%) patients, mostly psychiatric/psychological (11.5\%), urological (8.1\%) and gynecological (12.3\% of the women) (Table 5). In IBS-C psychiatric/ psychological and gynaecological consultations were more frequently requested than in NRC $(p<0.05)$.
Diagnostic tests were requested in $702 / 878(80.0 \%)$ of the patients. Table 6 shows the different tests requested in the whole sample and in the different diagnosis subgroups (IBS-C, FC and NRC). Fecal calprotectin was more frequently prescribed in IBS-C than in FC and NRC $(p<0.0001$ and $p<0.05$, respectively). Thyroid function tests $(p<0.05)$, serology for celiac disease $(p<0.005)$, lactose breath test $(p<$ $0.01)$ and glucose breath test $(p<0.05)$ were more frequently suggested in IBS-C than in FC, whereas in FC anorectal manometry was more frequently prescribed than in IBS-C $(p<0.05)$ and defecography more frequently than in NRC $(p<0.05)$. Abdominal ultrasonography was suggested in $22 \%$ of the patients without significant differences among groups.

Colonoscopy was suggested more in patients $\geq 50$ years than in those $<50$ years $(52.3 \%$ vs. $22.5 \% ; p<0.0001)$, more in males than in females $(51.2 \%$ vs. $35.6 \% ; p<0.001)$ and more often at first evaluation than at follow-up $(43.2 \%$ vs. $32.8 \% ; p<0.005)$. Also, routine blood tests

Table 3 PAC-SYM total score and abdominal, rectal and faecal symptoms subscales: mean values \pm SD in all patients and in IBS-C, FC and NRC subgroups

\begin{tabular}{lcllll}
\hline & ALL PATIENTS & IBS-C & FC & NRC & $p$-value \\
\hline Total score & $1.6 \pm 0.70$ & $1.75 \pm 0.70^{*}$ & $1.56 \pm 0.68$ & $1.31 \pm 0.70$ & $p<0.0001$ \\
Abdominal symptoms & $1.53 \pm 0.88$ & $1.91 \pm 0.74 \# \S$ & $1.37 \pm 0.88$ & $1.19 \pm 0.86$ & $p<0.0001$ \\
Rectal symptoms & $0.88 \pm 0.86$ & $0.98 \pm 0.92$ & $0.85 \pm 0.83$ & $0.70 \pm 0.78$ & $\mathrm{~ns}$ \\
Faecal symptoms & $2.09 \pm 0.91$ & $2.09 \pm 0.88$ & $2.13 \pm 0.92$ & $1.74 \pm 0.88 \wedge$ & $p<0.01$ \\
\hline
\end{tabular}

IBS-C irritable bowel syndrome with constipation, FC functional constipation, NRC patients do not accomplish Rome III criteria

${ }^{1} p$ values are referred to the differences between IBS-C, FC and NRC groups, in particular ${ }^{*} p<0.0001$ vs FC and NRC; \# $p<0.0001$ vs NRC; $\S p<0.05$ vs FC;

$\wedge p<0.01$ vs IBS-C and FC; ns: not statistically significant 
Table 4 PAC-QoL total score and subscales (mean values \pm SD) in all patients and in IBS-C, FC and NRC subgroups

\begin{tabular}{lcllll}
\hline & ALL PATIENTS & IBS-C & FC & NRC & $p$-value \\
\hline Total score & $1.77 \pm 0.69$ & $1.97 \pm 0.70$ & $1.71 \pm 0.68$ & $1.44 \pm 0.62^{*}$ & $p<0.001$ \\
Physical discomfort & $1.85 \pm 0.88$ & $2.13 \pm 0.82$ & $1.75 \pm 0.88$ & $1.42 \pm 0.82^{*}$ & $p<0.001$ \\
Psychosocial discomfort & $1.12 \pm 0.83$ & $1.38 \pm 0.83$ & $1.02 \pm 0.80$ & $0.77 \pm 0.73^{*}$ & $p<0.001$ \\
Worries and concerns & $1.72 \pm 0.92$ & $1.92 \pm 0.93$ & $1.65 \pm 0.90$ & $1.36 \pm 0.80^{*}$ & $p<0.001$ \\
Satisfaction & $2.90 \pm 0.71$ & $2.89 \pm 0.72$ & $2.92 \pm 0.69$ & $2.74 \pm 0.81$ & ns \\
\hline
\end{tabular}

IBS-C irritable bowel syndrome with constipation, FC functional constipation, NRC patients do not accomplish Rome III criteria

${ }^{1} p$ values are referred to the differences between IBS-C, FC and NRC groups, in particular

${ }^{*} p<0.001$ vs IBS-C and FC; ns: not statistically significant

(61.2\% vs. $46.6 \% ; p<0.0001)$, thyroid function tests (52.0\% vs. $40.2 \%, ;<0.001)$, carcinoembryonic antigen $(11.3 \%$ vs. $6.4 \% ; p<0.05)$, serology for celiac disease $(19.1 \%$ vs. $13.2 \% ; p<0.05)$; and stool culture and test for ova and parasites $(9.7 \%$ vs. $4.2 \% ; p<0.005)$ were requested more often at first evaluation than at follow-up. On the contrary defecography $(2.5 \%$ vs. $5.6 \% ; p<0.05)$ was suggested less frequently at first visit than at follow-up. Serology for celiac disease was suggested more frequently in patients $<50$ years old than in patients $\geq 50$ years old $(22.0 \%$ vs. $11.3 \%$; $p<0.0001$ ).

Table 7 shows the suggested therapies, overall and by diagnosis. In $863 / 878$ patients $(98.3 \%)$ at least one treatment was given. Lifestyle and dietary changes were the most frequent suggestions, whereas macrogol and fiber supplements were largely the most frequently prescribed substances.

Macrogol was suggested more frequently in FC (71.6\%) and IBS-C $(70.9 \%)$ than in NRC $(42.6 \% ; p<0.0001)$. A fiber supplements prescription was slightly more frequent in IBS-C, but no significant difference was detected among IBS-C, FC and NRC. In IBS-C antispasmodics were used more frequently compared to
FC and NRC (27.6\% vs. $11.7 \%$ vs. $11.1 \% ; p<0.0001$ and $p>0.05$, respectively). Antibloating agents $(29.1 \%$ vs. $18.6 \% ; p<0.005)$ and psychotherapy $(6.9 \%$ vs. $2.7 \% ; p<0.05)$ were most frequently prescribed in IBS-C than in FC, whereas pelvic floor rehabilitation was more frequently suggested in FC than in IBS-C $(22.2 \%$ vs. $14.6 \% ; p<0.05)$.

Lactulose/lactitole ( $8.6 \%$ vs. $4.3 \% ; p<0.05)$, suppositories/micro-enemas $(26.4 \%$ vs. $18.2 \%$; $p<0.005)$, intestinal antibiotics $(9.0 \%$ vs. $3.0 \% ; p<0.0005)$, antidepressants $(10.0 \%$ vs. $3.0 \% ; p<0.0001)$, anxiolytics $(15.9 \%$ vs. 8.1 ; $p<0.001)$ and pelvic floor rehabilitation $(22.0 \%$ vs. $15.7 \% ; p<0.05)$ were more frequently suggested in patients $\geq 50$ years than in patients $<50$ years, whereas antispasmodics were more frequently prescribed in patients $<50$ years than in patients $\geq 50$ years $(20.0 \%$ vs. $13.8 \% ; p<0.05)$.

Enemas and micro-enemas/suppositories were mainly prescribed not on a daily basis but usually every other day or on demand (24.2\% and $19.7 \%$, respectively). Lifestyle changes $(87.5 \%$ vs. $80.9 \% ; p<0.05)$ and dietary suggestions $(91.1 \%$ vs. $83.9 \% ; p<0.05)$ were more frequently prescribed in males than in females, but anorectal surgery only in females $(2.8 \%)$.

Table 5 Specialist consultations requested by the gastroenterologists after their visit

\begin{tabular}{|c|c|c|c|c|c|}
\hline CONSULTATION & 878 pts. (\%) & IBS-C (\%) & FC (\%) & NRC (\%) & $p$-value ${ }^{1}$ \\
\hline Psychiatrist/psychologist & $101(11.5)$ & 16.0 & 10.0 & $3.7^{*}$ & $<0.01$ \\
\hline Gynaecologist ${ }^{a}$ & $87(12.3)$ & 15.4 & 11.6 & $2.6^{*}$ & $<0.05$ \\
\hline Urologist & $71(8.1)$ & 8.0 & 8.4 & 5.6 & ns \\
\hline Surgeon & $66(7.5)$ & 6.6 & 7.8 & 9.3 & ns \\
\hline Physiatrist/Physiotherapist & $49(5.6)$ & 6.2 & 5.8 & - & ns \\
\hline Dietician & $46(5.2)$ & 4.0 & 5.8 & 5.6 & ns \\
\hline Rheumatologist & $15(1.7)$ & 2.6 & 1.3 & 1.9 & ns \\
\hline Neurological & $15(1.7)$ & 1.8 & 1.6 & 1.9 & ns \\
\hline Other & $17(1.9)$ & 2.6 & 1.8 & - & ns \\
\hline
\end{tabular}

IBS-C irritable bowel syndrome with constipation, FC functional constipation, NRC patients do not accomplish Rome III criteria ${ }^{a}$ calculated on the women sample visited

${ }^{1} p$ values are referred to the differences between IBS-C, FC and NRC groups, in particular; * ${ }^{2}$ IBS-C and FC; ns: not statistically significant 
Table 6 Diagnostic test requested by the gastroenterologist after their visit

\begin{tabular}{|c|c|c|c|c|c|}
\hline DIAGNOSTIC TEST & 878 pts.(\%) & IBS-C (\%) & FC (\%) & NRC (\%) & $p$-value \\
\hline Routine blood tests & $472(53.8)$ & 58.9 & 51.6 & 50.0 & ns \\
\hline Thyroid function tests & $400(45.6)$ & $52.4 \#$ & 43.2 & 35.2 & $<0.05$ \\
\hline Colonoscopy & $339(38.6)$ & 34.6 & 40.6 & 38.9 & ns \\
\hline Anorectal manometry & $306(34.9)$ & $29.8 \#$ & 38.6 & 22.2 & $<0.01$ \\
\hline Colonic transit time & $228(26.0)$ & 30.6 & 24.6 & 16.7 & ns \\
\hline Abdominal ultrasonography & $193(22.0)$ & 22.6 & 22.2 & 16.7 & ns \\
\hline RX Defecography & $167(19.0)$ & 16.4 & $21.5^{\circ}$ & 7.4 & $<0.05$ \\
\hline Faecal blood test & $153(17.4)$ & 14.9 & 18.8 & 16.7 & ns \\
\hline Coeliac serology & $142(16.2)$ & $22.6 \wedge$ & 13.1 & 14.8 & $<0.005$ \\
\hline $\begin{array}{l}\text { Carcinoembryonic } \\
\text { antigen assay }\end{array}$ & $78(8.9)$ & 6.6 & 9.8 & 11.1 & ns \\
\hline Faecal calprotectin & $64(7.3)$ & $15.3 * * *$ & 3.8 & 1.9 & $<0.0001$ \\
\hline $\begin{array}{l}\text { Stool culture, test for ova } \\
\text { and parasites }\end{array}$ & $62(7.1)$ & 6.6 & 8.0 & - & ns \\
\hline Lactose Breath Test & $35(4.0)$ & $7.3 \S$ & 2.7 & - & $<0.005$ \\
\hline MR Defecography & $33(3.8)$ & 2.6 & 4.2 & 5.6 & ns \\
\hline Trans-anal ultrasound & $30(3.4)$ & 4.7 & 2.9 & 1.9 & ns \\
\hline Rectosigmoidoscopy & $22(2.5)$ & 2.9 & 2.6 & - & ns \\
\hline Virtual colonoscopy & $19(2.2)$ & 1.8 & 2.4 & 1.9 & ns \\
\hline Barium Enema & $14(1.6)$ & 1.1 & 1.8 & 1.9 & ns \\
\hline Glucose Breath test & $12(1.4)$ & $2.9 \#$ & 0.7 & - & $<0.05$ \\
\hline Colonic manometry & $12(1.4)$ & 1.8 & 1.1 & 1.9 & ns \\
\hline $\begin{array}{l}\text { Anal Sphincter } \\
\text { Electromyography }\end{array}$ & $5(0.6 \%)$ & 0.7 & 0.6 & - & ns \\
\hline Other & $34(3.9)$ & 4.7 & 3.6 & 1.9 & ns \\
\hline
\end{tabular}

IBS-C irritable bowel syndrome with constipation, $F C$ functional constipation, NRC patients do not accomplish Rome III criteria

${ }^{1} p$ values are referred to the differences between IBS-C, FC and NRC groups, in particular

$\# p<0.05$ vs $\mathrm{FC}_{;}{ }^{*} p<0.0001$ vs $\mathrm{FC}_{;}{ }^{* *} p<0.05$ vs NRC; $\wedge p<0.005$ vs $\mathrm{FC} ; \S p<0.01$ vs $\mathrm{FC}_{i}{ }^{\circ} p<0.05$ vs NRC; ns: not statistically significant

Probiotics were most frequently prescribed at first visit than at follow-up $(40.9 \%$ vs. $31.5 \% ; p<0.01)$, whereas prucalopride and pelvic floor rehabilitation were more often prescribed during a follow-up visit than at first evaluation $(20.1 \%$ vs. $10.6 \%, p<0.0001$; $23.8 \%$ vs. $15.4 \%, p<0.005$, respectively).

A mix of suggestions and drugs was used in many patients: in $59.5 \%$ lifestyle suggestions, changes in diet and macrogol; in $50.8 \%$ lifestyle suggestions, changes in diet and fiber supplementation; in $37.2 \%$ changes in diet, fiber supplementation and macrogol; in $37.1 \%$ lifestyle suggestions, fiber supplementation and macrogol; in $33.3 \%$ lifestyle suggestions, changes in diet and probiotics.

\section{Discussion}

The present study conveys an important educational message for general practitioners, who see the majority of constipated patients, and for other specialists who could visit patients for possible comorbidities: when collecting the patient's history, the presence of constipation should be accurately searched and treated (if possible). Waiting so many years before sending constipated patients to a gastroenterologist simply means worsening a patient's symptoms and his/her QoL [4] and increasing the risk to develop important anatomical alterations such as perineal descent, rectocele, rectal intussusceptions, prolapse, enterocele or sigmoidocele, or increase his/her cardiovascular mortality [17].

Rome criteria seemed accurate to identify constipated patients, since only $6.2 \%$ showed NRC.

NRC patients were usually older and often male than IBS-C, and reported fewer and less severe symptoms, softer stools and a better QoL than FC and IBS-C. On the other hand, IBS-C patients were younger and more often female, reported more severe symptoms, harder stools and a worse QoL than NRC 
Table 7 Suggested therapies requested by the gastroenterologist after their visit

\begin{tabular}{|c|c|c|c|c|c|}
\hline THERAPIES & 878 pts.(\%) & IBS-C (\%) & FC (\%) & NRC (\%) & $p$-value $^{1}$ \\
\hline Life style recommendations & $722(82.2)$ & 84.7 & 81.8 & 74.1 & ns \\
\hline Dietary suggestions & $749(85.3)$ & 85.5 & 85.8 & 79.6 & ns \\
\hline Fibre supplements & $489(55.7)$ & 60.7 & 53.2 & 55.6 & ns \\
\hline Herbal remedies & $46(5.2)$ & 6.2 & 4.9 & 3.7 & ns \\
\hline Probiotics & $318(36.2)$ & 40.4 & 33.5 & 42.6 & ns \\
\hline Lactulose/lactitole & $58(6.6)$ & 4.7 & 7.8 & 3.7 & ns \\
\hline Macrogol & $609(69.4)$ & 71.6 & 70.9 & $42.6 \#$ & $<0.0001$ \\
\hline Saline laxatives & $31(3.5)$ & 4.0 & 3.5 & 1.9 & ns \\
\hline Stimulant laxatives & $55(6.3)$ & 6.2 & 6.7 & 1.9 & ns \\
\hline Softening laxatives & $46(5.2)$ & 5.1 & 5.7 & 1.9 & ns \\
\hline Prucalopride & $126(14.4)$ & 13.1 & 15.7 & 7.4 & ns \\
\hline Suppositories/micro-enemas & $198(22.6)$ & 23.6 & 21.3 & 29.6 & ns \\
\hline Enemas & $238(27.1)$ & 29.5 & 26.6 & 20.4 & ns \\
\hline Antispasmodics & $146(16.6)$ & $27.6 * * *$ & 11.7 & 11.1 & $<0.0001$ \\
\hline Anti-bloating agents & $191(21.8)$ & $29.1 \wedge$ & 18.6 & 16.7 & $<0.005$ \\
\hline Intestinal antibiotics & $55(6.3)$ & 7.3 & 5.5 & 9.3 & ns \\
\hline Anxiolytics & $108(12.3)$ & 14.6 & 11.5 & 9.3 & ns \\
\hline Antidepressants & $60(6.8)$ & 8.0 & 6.0 & 9.3 & ns \\
\hline Psychotherapy & $35(4.0)$ & $6.9 \S$ & 2.7 & 1.9 & $<0.05$ \\
\hline Pelvic floor rehabilitation & 169 (19.3) & 14.6 & $22.2^{\circ}$ & 13.0 & $<0.05$ \\
\hline Sacral neurostimulation & $3(0.3)$ & $/ /$ & 0.4 & 1.9 & ns \\
\hline Anorectal surgery & $20(2.3)$ & 1.5 & 2.7 & 1.9 & ns \\
\hline Colectomy & $1(0.1)$ & $/ /$ & // & 1.9 & ns \\
\hline Other & $18(2.1)$ & 2.2 & 2.2 & $/ /$ & ns \\
\hline
\end{tabular}

IBS-C irritable bowel syndrome with constipation, FC functional constipation, NRC patients do not accomplish Rome III criteria ${ }^{1} p$ values are referred to the differences between IBS-C, FC and NRC groups, in particular

$\# p<0.0001$ vs IBS-C and NRC; ${ }^{*} p<0.0001$ vs FC; ${ }^{* *} p<0.05$ vs NRC; $\wedge p<0.005$ vs FC; $\S p<0.05$ vs $\mathrm{FC}^{\circ}{ }^{\circ} p<0.05$ vs IBS-C; ns: not statistically significant

and FC. Our results show that Rome III criteria identify patients with more severe constipation.

Recently the new Rome IV criteria have been published [18]. No substantial differences have been introduced regarding definition and classification of functional constipation: simply they state that "abdominal pain and/or bloating may be present but are not predominant symptoms (ie, the patient does not meet criteria for IBS)". Regarding IBS the term discomfort was eliminated and the frequency of abdominal pain became at least 1 day per week instead of 3 days per month. However we think that these changes would not have a significant impact on the results of our study.

PAC-SYM and PAC-QoL questionnaires showed higher scores in IBS-C group than in FC and NRC: PAC-SYM abdominal symptom subscale, PAC-QoL mean total score, physical discomfort, psychosocial discomfort and worries and concerns subscales were found to be higher in IBS-C. This reflects the close association between the first four items of PAC-SYM (abdominal discomfort, abdominal pain, bloating, stomach cramps) and the typical symptoms of IBS. These symptoms are likely responsible for the lower QoL in IBS-C. Thus, the increase in perception of constipation severity increases impairment of the QoL, also increasing request of diagnostic tests and therapies.

Different clinical characteristics, such as type of constipation and comorbidities, may influence the clinical approach of the gastroenterologists; thus, our primary endpoint was to assess the diagnostic tools and treatment suggested by Italian gastroenterologists to their constipated patients, and the impact on the clinical subgroups.

A surprising result, deserving discussion, is that DRE was not performed in more than $40 \%$ of the patients, independently from being at first visit or at 
follow-up. DRE is the simplest and the most immediate method to assess anal tone and to collect information about the pelvic floor conditions and to detect early forms of rectal cancer or benign diseases [19-22]. These data should be carefully taken into account when carrying out educational campaigns on the diagnosis and treatment of CC.

The presence of comorbidities was likely the main reason for the more frequent requested consultations (psychiatric/ psychological, urological, gynecological) underlining the need for a stronger collaboration among different specialists for the correct management of $\mathrm{CC}$, possibly creating multidisciplinary teams.

Regarding the attitude towards diagnostic tests, we want to stress that in about four out of five patients gastroenterologists were not so confident on Rome III criteria, and prescribed at least one diagnostic test, more often in patients at first evaluation, mainly blood tests, but also colonoscopy (requested more frequently in patients older than 50 years), anorectal manometry and measurement of colonic transit time. As already shown in previous studies in a general practitioner setting, abdominal ultrasound, although not recommended by current guidelines, was quite frequently requested, especially when abdominal pain is present [23-26].

To exclude conditions potentially mimicking IBS, laboratory and breath tests were more frequently requested in these patients, whereas in FC, defecography and anorectal manometry were more frequently requested to evaluate the presence of dyssynergic defecation. In NRC patients fewer diagnostic tests were overall required, probably due to less severe symptoms and lesser impairment of the QoL.

Overall, dietetic and lifestyle suggestions were the most frequently suggested therapeutic options ( $>90 \%$ of the patients) (Table 7). However, in the present study, the gastroenterologists were often not confident that these could be sufficient to solve the problem and used macrogol as the first line laxative, both in association with dietetic and lifestyle suggestion and fibers.

Macrogol is effective and safe, and new liquid formulations make it easier to dose; because taste is an important factor for patients' adherence, particularly for long-time treatment, the formulations without aroma made it more acceptable to patients [27]. On the other hand further increasing fibers intake could induce bloating and abdominal discomfort without improving colonic transit time [28]. To control the different symptoms of IBS (mainly abdominal pain and bloating) gastroenterologists also used antispasmodic drugs, psychotherapy and anti-bloating agents, whereas pelvic floor rehabilitation was suggested more often in FC patients, in whom functional defecation disorders should be more frequent.

Surgery procedures (and sacral neurostimulation) were infrequently suggested by gastroenterologists.

The gastroenterologists involved in this study rarely prescribed laxatives such as lactulose/lactitole, and stimulant, emollient or saline laxatives which still represent the most used laxatives in Italy. These drugs, which cover about $40 \%$ of the Italian market [29], are more often prescribed by general practitioners [23] and other specialists than gastroenterologists.

Prucalopride, recently available on the Italian market, was prescribed in about $13 \%$ of patients although it was considered, probably because expensive, a second/third line treatment, and prescribed more frequently at a follow-up. At the time of the study, linaclotide was not yet available on the Italian market.

As previously reported for diagnostic tools, the amount of therapy prescribed also increased by increasing PAC-SYM and PAC-QoL scores; in NRC patients, who displayed lighter symptoms, fewer therapies were suggested. In conclusion, in our country a gastroenterological evaluation of $\mathrm{CC}$ is often delayed in patients with long lasting symptoms, colonoscopy and blood tests are considered a "first line" diagnostic tool, and DRE is insufficiently performed. Furthermore, constipation is associated with several comorbidities in most patients. Among Italian gastroenterologists macrogol is the most frequently used laxative, while in IBS-C patients a larger amount of drugs is prescribed than in FC and NRC patients.

The study also provides several educational ideas to improve the diagnostic and therapeutic approach to $\mathrm{CC}$ : general practitioners and other specialists should be suggested to address earlier such patients to a gastroenterologist before long-term complications occur. DRE should be performed in all patients, while echography usefulness should be resized.

\section{Conclusions}

Chronic constipation is a common disorder that has a remarkable impact on the quality of life. We report on diagnostic and therapeutical experiences of Italian gastroenterologists.

Patients with irritable bowel syndrome with constipation reported more severe symptoms and worsened quality of life than functional constipation. Colonoscopy and blood tests were the most prescribed tests and Macrogol was the most prescribed laxative.

This study can provide several educational ideas to improve the diagnostic and therapeutic approach to Chronic Constipation. 


\section{Appendix}

\section{ChroCoDiTE Study Group Members - Collaborators}

\begin{tabular}{|c|c|}
\hline Last Name, First Name, Degree & Affiliation \\
\hline Bellini Massimo, MD & U.O. Gastroenterologia Universitaria - AOU Pisana, Pisa \\
\hline Usai Satta Paolo, MD & S.C. Gastroenterologia - Azienda Ospedaliera G. Brotzu - Cagliari \\
\hline Bove Antonio, MD & $\begin{array}{l}\text { U.O. Gastroenterologia ed Endoscopia Digestiva, Dipartimento di Gastroenterologia - AORN "A. } \\
\text { Cardarelli", Napoli }\end{array}$ \\
\hline Bocchini Renato, MD & $\begin{array}{l}\text { Fisiopatologia ed Endoscopia Digestiva. Gastroenterologia ed Endoscopia Digestiva, Casa di Cura } \\
\text { Malatesta Novello, Cesena }\end{array}$ \\
\hline Battaglia Edda, MD & S.O.C Gastroenterologia, Ospedale Cardinal Massaja, Asti \\
\hline Alduini Pietro, MD & U.O. Gastroenterologia; Ospedale di Lucca \\
\hline Galeazzi Francesca, MD & U.O. Gastroenterologia Universitaria - Azienda Ospedaliero Universitaria Padova \\
\hline Bassotti Gabrio, MD & Sezione di Gastroenterologia ed Epatologia, Dipartimento di Medicina Interna, Università di Perugia \\
\hline Balzano Antonio, MD & Azienda Ospedaliera di Rilevanza Nazionale "A. Cardarelli", Napoli \\
\hline Portincasa Piero, MD & Clinica Medica "A. Murri", Dipartimento di Scienze Biomediche e Oncologia Umana, Università di Bari \\
\hline Bonfrate Leonilde, MD & Clinica Medica "A. Murri", Dipartimento di Scienze Biomediche e Oncologia Umana, Università di Bari \\
\hline D’Alba Lucia; MD & U.O.C. Gastroenterologia ed Endoscopia Digestiva, Az. Ospedaliera San Giovanni Addolorata - Roma \\
\hline Badiali Danilo, MD & Dip. Medicina Interna e Specialità Mediche, La Sapienza, Roma \\
\hline Marchi Santino, MD & U.O. Gastroenterologia Universitaria - AOU Pisana, Pisa \\
\hline Gambaccini Dario, MD & U.O. Gastroenterologia Universitaria - AOU Pisana, Pisa \\
\hline Neri Maria Cristina, MD & Ambulatorio Gastroenterologia ed Endoscopia digestiva - Pio Albergo Trivulzio, Milano, \\
\hline Muscatiello Nicola, MD & U.O. Gastroenterologia Universitaria, Foggia \\
\hline Di Stefano Michele, MD & U.O. Medicina Interna I, Fondazione IRCCS Policlinico "S.Matteo", Pavia. \\
\hline Giannelli Claudio, MD & U.O.C. di Gastroenterologia Riabilitativa - Az. Ospedaliera San Camillo - Forlanini, ROMA \\
\hline Goffredo Fabio, MD & U.O.C di Gastroenterologia Riabilitativa - Az. Ospedaliera San Camillo - Forlanini, ROMA \\
\hline Turco Luigi, MD & S. S. Endoscopia Digestiva; U. O. C. Chirurgia Generale; P. O. Copertino, Lecce \\
\hline Camilleri Salvatore, MD & U.O.C. di gastroenterologia, Ospedale M. Raimondi San Cataldo, Caltanissetta \\
\hline Ceccarelli Giovanni, MD & U.O.C. di Gastroenterologia ed Endoscopia Digestiva, Ospedale della Versilia - Viareggio \\
\hline lovino Paola, MD & Dipartimento di Medicina e Chirurgia-Università di Salerno \\
\hline Montalbano Luigi Maria, MD & U.O.C. di Gastroenterologia, Ospedali Riuniti Villa Sofia-Cervello Palermo \\
\hline Morreale Gaetano Cristian, MD & Gastroenterologia ed Epatologia; Policlinico Palermo \\
\hline Rentini Silvia, MD & $\begin{array}{l}\text { U.O.C. Gastroenterologia ed Endoscopia Operativa, Dipartimento Oncologico; } \\
\text { Azienda Ospedaliera Universitaria Senese - Siena }\end{array}$ \\
\hline Savarino Vincenzo, MD & U.O. Clinica Gastroenterologia con Endoscopia - IRCCS AO Universitaria San Martino - IST - Genova \\
\hline Segato Sergio, MD & UO Gastroenterologia ed Endoscopia Digestiva. AOU Macchi, Varese \\
\hline Buscarini Elisabetta, MD & U.O. Gastroenterologia ed Endoscopia Digestiva, Ospedale Maggiore- Crema \\
\hline Manfredi Guido, MD & U.O. Gastroenterologia ed Endoscopia Digestiva, Ospedale Maggiore- Crema \\
\hline Cannizzaro Renato, MD & $\begin{array}{l}\text { SOC. Gastroenterologia Oncologica, Centro di Riferimento Oncologico - Istituto Nazionale Tumori } \\
\text { IRCCS, Aviano }\end{array}$ \\
\hline Passaretti Sandro, MD & U.O. Gastroenterologia Ospedale Universitario San Raffaele, Milano, Italy \\
\hline Alessandri Matteo, MD & U.O. Gastroenterologia Ospedale Universitario San Raffaele, Milano, Italy \\
\hline Corti Federico, MD & U.O.C. di Gastroenterologia ed Endoscopia Digestiva, Ospedale della Versilia - Viareggio \\
\hline Cuomo, Rosario, MD & Dipartimento di Medicina Clinica e Sperimentale, Università Federico II, Napoli \\
\hline Zito Francesco Paolo, MD & Dipartimento di Medicina Clinica e Sperimentale, Università Federico II, Napoli \\
\hline Mellone Carmine, MD & UOS di Endoscopia Digestiva. Ospedali della Valdichiana, Montepulciano \\
\hline Barbera Roberta, MD & Ospedale San Giuseppe Multimedica - Milano \\
\hline
\end{tabular}


(Continued)

Milazzo Giuseppe, MD

Pucciani Filippo, MD

Soncini Marco, MD

Lai Maria Antonia, MD

Ruggeri Maurizio, MD

Savarese Maria Flavia, MD

De Bona Manuela, MD

Surrenti Elisabetta, MD

Arini Andrea, MD

Dinelli Marco, MD

Leandro Gioacchino, MD

Peralta Sergio, MD

Manta Raffaele, MD

Quartini Mariano, MD

Torresan Francesco, MD

Vilardo Luigi, MD

Pulvirenti D'Urso Antonino, MD

Tarantino Ottaviano, MD

Noris Roberto Antonio, MD

Monica Fabio, MD

Carrara Maurizio, MD

Losco Alessandra, MD

Lauri Adriano, MD

Neri Matteo, MD

Grassini Mario, MD
UOC Medicina e Lungodegenza, Ospedale Vittorio Emanuele III, Salemi

Dipartimento di Chirurgia e Medicina Traslazionale - Università di Firenze.

UOC Gastroenterologia, Ospedale San Carlo - Milano

Dipartimento di Medicina Interna A.O.U. Policlinico di Monserrato, Università di Cagliari

U.O. Gastroenterologia, Ospedale Sant'Andrea - Roma

U.O.C. Endoscopia Digestiva e Gastroenterologia - A.O. Istituti Ospitalieri di Cremona

U.O.C. Gastroenterologia, Ospedale S. Maria Del Prato, Feltre

SOS Fisiopatologia dell'apparato digerente e motilità, AOU Careggi - Firenze

U.O. Gastroenterologia ed Epatologia; Policlinico Paolo Giaccone - Palermo

U.O. Endoscopia Digestiva, Azienda Ospedaliera San Gerardo, Monza

Dipartimento di gastroenterologia, IRCCS De Bellis - Castellana Grotte

U.O.C di Gastroenterologia ed Epatologia, A.O.U. Policlinico Paolo Giaccone - Palermo

U.O.C. Endoscopia Digestiva ed Interventistica Ospedale Niguarda Ca' Granda, Milano

S.C. Epatologia e Gastroenterologia, A.O. S. Maria, Terni

Dipartimento di Medicina Interna e Gastroenterologia , Policlinico S.Orsola-Malpighi - Università di Bologna,

U.O.S. Gastroenterologia Ospedale Generale Ferrari, Castrovillari

U.O. Chirurgia, Ospedale Nuovo Garibaldi - Catania

U.O. Gastroenterologia, Ospedale S. Giuseppe, Empoli

U.O.C. di Gastroenterologia ed Endoscopia Digestiva - A.O. Bolognini - Seriate

S.C. Gastroenterologia ed Endoscopia Digestiva - AOU - Ospedale di Cattinara - Trieste

U.O.S.D. di Gastroenterologia Ospedale Orlandi, Bussolengo

Gastroenterologia Ospedale San Paolo - MILANO

U.O.C. Gastroenterologia ed Endoscopia Digestiva, Ospedale Civile Spirito Santo, Pescara

Dipartimento di Medicina e Scienze dell'Invecchiamento \& Ce.S.l., Università G. D'Annunzio, Chieti.

S.O.C. Gastroenterologia, Ospedale Cardinal Massaja, Asti

\section{Additional file}

Additional file 1: Data: the PAC-SYM and PAC-QoL total and domain scores. (DOC $17 \mathrm{~kb}$ )

\section{Abbreviations}

AIGO: Italian association of hospital gastroenterologists and endoscopists; BMI: Body mass index; CC: Chronic constipation; DRE: Digital rectal examination; FC: Functional constipation; IBS-C: Irritable bowel syndrome with constipation; NRC: No Rome constipation; PAC-QoL: The patient assessment of constipation-quality of life; PAC-SYM: Patient assessment of constipation-symptoms; QoL: Quality of life.

\section{Acknowledgments}

The authors are grateful to Dr. Elena Pasquali for her valuable help in carrying out the statistical analysis.

The members of the ChroCoDiTE StudyGroup are listed in Appendix and searchable through their individual PubMed records.

\section{Funding}

None.

\section{Availability of data and materials}

The datasets analysed during the current study are available from the corresponding author on reasonable request.

\section{Authors' contributions}

MB, PUS, GB, participated in study concept and design, data analysis, interpretation of results, manuscript drafting and approved the final version of the manuscript. $A B, R B$ and $F G$ contributed to the interpretation of results, provided critical revisions to manuscript drafts and approved the final version of the manuscript. EB and PA participated in study concept and design, data collection, interpretation of results, provided critical revisions to manuscript drafts and approved the final version of the manuscript. All members of the ChroCoDiTE study group participated in data collection, provided critical revisions to manuscript drafts and approved the final version of the manuscript.

\section{Competing interests}

The authors declare that they have no competing interests.

\section{Consent for publication}

Not applicable.

\section{Ethical approval and consent to participate}

The study protocol was approved by the Ethical Committee of Pisa (study number 3841/2013 approved on March $21^{\text {st }}, 2013$ ) and was carried out in accordance with the Helsinki Declaration (Sixth Revision, Seoul 2008). A signed informed consent was obtained from each participant.

\section{Author details}

${ }^{1}$ Gastrointestinal Unit, Department of Gastroenterology, University of Pisa, Via Paradisa, 2, 56127 Pisa, Italy. ${ }^{2}$ Brotzu Hospital, Gastroenterology Unit, Cagliari, Italy. ${ }^{3}$ AORN "A. Cardarelli", Naples, Italy. ${ }^{4}$ Malatesta Novello, Private Hospital, 
Cesena, Italy. ${ }^{5}$ Division of Gastroenterology, Department of Surgery, Oncology and Gastroenterology, University of Padua, Padua, Italy. ${ }^{6}$ Cardinal Massaia Hospital, Gastroenterology Unit, Asti, Italy. ${ }^{7}$ San Luca Hospital, Digestive Endoscopy Unit, Lucca, Italy. ${ }^{8}$ Gastroenterology and Digestive Endoscopy Unit, Maggiore Hospital, Crema, Italy. ${ }^{9}$ Gastrointestinal and Hepatology Section, Clinical \& Experimental Medicine, Perugia, Italy.

Received: 19 July 2016 Accepted: 6 December 2016

Published online: 14 January 2017

\section{References}

1. Lacy BE, Brunton SA. Partnering with gastroenterologists to evaluate patients with chronic constipation. Med Gen Med. 2005;7:19. PMID: 16369398.

2. Lindberg G, Hamid SS, Malfertheiner P, Thomsen OO, Fernandez LB, Garisch J, Thomson A, Goh KL, et al. World Gastroenterology Organisation global guideline: Constipation-a global perspective. J Clin Gastroenterol. 2011;45: 483-7. doi:10.1097/MCG.0b013e31820fb914. PMID: 21666546.

3. Nellesen D, Yee K, Chawla A, Lewis BE, Carson RT. A systematic review of the economic and humanistic burden of illness in irritable bowel syndrome and chronic constipation. J Manag Care Pharm. 2013;19:755-64. PMID: 24156644.

4. Neri L, Basilisco G, Corazziari E, Stanghellini V, Bassotti G, Bellini M, Perelli I, Cuomo R, LIRS study group. Constipation severity is associated with productivity losses and healthcare utilization in patients with chronic constipation. United European Gastroenterol J. 2014;2:138-47. do:10.1177/2050640614528175. PMID: 24953097.

5. Nyrop KA, Palsson OS, Levy RL, Von Korff M, Feld AD, Turner MJ, Whitehead WE. Costs of health care for irritable bowel syndrome, chronic constipation, functional diarrhoea and functional abdominal pain. Aliment Pharmacol Ther. 2007;26:237-48. doi:10.1111/j.1365-2036.2007.03370.x. PMID: 17593069.

6. Bharucha AE, Pemberton JH, Locke 3rd GR. American Gastroenterological Association technical review on constipation. Gastroenterology. 2013;144: 218-38. doi:10.1053/j.gastro.2012.10.028. PMID: 23261065.

7. McCrea GL, Miaskowski C, Stotts NA, Macera L, Varma MG. A review of the literature on gender and age differences in the prevalence and characteristics of constipation in North America. J Pain Symptom Manage. 2009;37:737-45. doi:10.1016/j.jpainsymman.2008.04.016. PMID: 18789639.

8. Peppas G, Alexiou VG, Mourtzoukou E, Falagas ME. Epidemiology of constipation in Europe and Oceania: a systematic review. BMC Gastroenterol. 2008;8:5. doi:10.1186/1471-230X-8-5. PMID: 18269746.

9. Suares NC, Ford AC. Prevalence of, and risk factors for, chronic idiopathic constipation in the community: systematic review and meta-analysis. Am J Gastroenterol. 2011;106:1582-91. doi:10.1038/ajg.2011.164. quiz 1, 92. PMID: 21606976.

10. Higgins PD, Johanson JF. Epidemiology of constipation in North America: a systematic review. Am J Gastroenterol. 2004;99:750-9. PMID: 15089911.

11. Wald A, Scarpignato C, Mueller-Lissner S, Kamm MA, Hinkel U, Helfrich I, Schuijt C, Mandel KG. A multinational survey of prevalence and patterns of laxative use among adults with self-defined constipation. Aliment Pharmacol Ther. 2008;28:917-30. doi:10.1111/j.1365-2036.2008.03806.x. [PMID: 18644012.

12. Longstreth GF, Thompson WG, Chey WD, Houghton LA, Mearin F, Spiller RC. Functional bowel disorders. Gastroenterology. 2006;130:1480-91. PMID: 16678561.

13. Gambaccini D, Racale C, Salvadori S, Bassotti G, Pucciani F, Battaglia E, Bocchini R, Bove A, Alduini P, Marchi S, Bellini M. Sa2033 Chronic Constipation: ROME III Criteria and What Patients Think. Are We Talking the Same Language? Gastroenterology. 2014;146:S-360.

14. Lewis SJ, Heaton KW. Stool form scale as a useful guide to intestinal transit time. Scand J Gastroenterol. 1997;32:920-4. PMID: 9299672.

15. Frank L, Kleinman L, Farup C, Taylor L, Miner Jr P. Psychometric validation of a constipation symptom assessment questionnaire. Scand J Gastroenterol. 1999;34:870-7. PMID: 10522604.

16. Marquis P, De La Loge C, Dubois D, McDermott A, Chassany O. Development and validation of the Patient Assessment of Constipation Quality of Life questionnaire. Scand J Gastroenterol. 2005;40:540-51. PMID: 16036506.

17. Bassotti G. Being constipated: a bad omen for your cardiovascular system? Atherosclerosis. 2016;245:240-1. doi:10.1016/j.atherosclerosis.2015.10.001. PMID: 26684285

18. Lacy BE, Mearin F, Chang L, Chey WD, Lembo AJ, Simren M, Spiller R. Gastroenterology. 2016;150:1393-407. doi:10.1053/j.gastro.2016.02.031.

19. Eckardt VF, Kanzler G. Prevention and early recognition of colorectal carcinoma. Dtsch Med Wochenschr. 1995;120:417-22. PMID: 7705204.
20. Talley NJ. How to do and interpret a rectal examination in gastroenterology Am J Gastroenterol. 2008;103:820-2. doi:10.1111/j.1572-0241.2008.01832.x. [PMID: 18397419.

21. Gupta PJ. A review of ano-rectal disorders and their treatment. Bratisl Lek Listy. 2006;107:323-31. PMID: 17125068.

22. Wong RK, Drossman DA, Bharucha AE, Rao SS, Wald A, Morris CB, Oxentenko AS, Ravi K, Van Handel DM, Edwards H, Hu Y, Bangdiwala S. The digital rectal examination: a multicenter survey of physicians' and students' perceptions and practice patterns. Am J Gastroenterol. 2012;107:1157-63. doi:10.1038/ajg.2012.23. PMID: 22858996.

23. Bellini M, Gambaccini D, Salvadori S, Tosetti C, Urbano MT, Costa F, Monicelli P, Mumolo MG, Ricchiuti A, De Bortoli N, Marchi S. Management of chronic constipation in general practice. Tech Coloproctol. 2014;18:543-9. doi:10.1007/s10151-013-1093-9. PMID: 24272606.

24. Bellini M, Tosetti C, Costa F, Tosetti C, Urbano MT, Costa F, Monicelli P, Mumolo MG, Ricchiuti A, Bruzzi P, Marchi S. The general practitioner's approach to irritable bowel syndrome: from intention to practice. Dig Liv Dis. 2005;37:934-9. PMID: 16243592

25. Bove A, Bellini M, Battaglia E, Bocchini R, Gambaccini D, Bove V, Pucciani F, Altomare DF, Dodi G, Sciaudone G, Falletto E, Piloni V. Consensus statement AIGO/SICCR diagnosis and treatment of chronic constipation and obstructed defecation (part II: treatment). World J Gastroenterol. 2012;18: 4994-5013. doi:10.3748/wjg.v18.i36.4994. PMID: 23049207.

26. Tack J, Muller-Lissner S, Stanghellini V, Boeckxstaens G, Kamm MA, Simren M, Galmiche JP, Fried M. Diagnosis and treatment of chronic constipation-a European perspective. Neurogastroenterology Motil. 2011;23:697-710. doi:10.1111/j.1365-2982.2011.01709.x. PMID: 21605282.

27. Lam TJ, Mulder CJ, Felt-Bersma RJ. Differences in taste between three polyethylene glycol preparations: a randomized double-blind study. Patient Prefer Adherence. 2011;5:423-6. doi:10.2147/PPA.S22780. PMID: 21949605.

28. McRorie Jr JW. Evidence-Based Approach to Fiber Supplements and Clinically Meaningful Health Benefits, Part 2: What to Look for and How to Recommend an Effective Fiber Therapy. Nutr Today. 2015;50:90-7. doi:10.1097/NT.0000000000000089. PMID: 25972619.

29. IMS Health. Intercontinental Marketing Services. Available at: http://www. imshealth.com.

\section{Submit your next manuscript to BioMed Central and we will help you at every step:}

- We accept pre-submission inquiries

- Our selector tool helps you to find the most relevant journal

- We provide round the clock customer support

- Convenient online submission

- Thorough peer review

- Inclusion in PubMed and all major indexing services

- Maximum visibility for your research

Submit your manuscript at www.biomedcentral.com/submit
C Biomed Central 